\title{
Spawning behavior of the sand dollar Sculpsitechinus auritus (Leske, 1778)
}
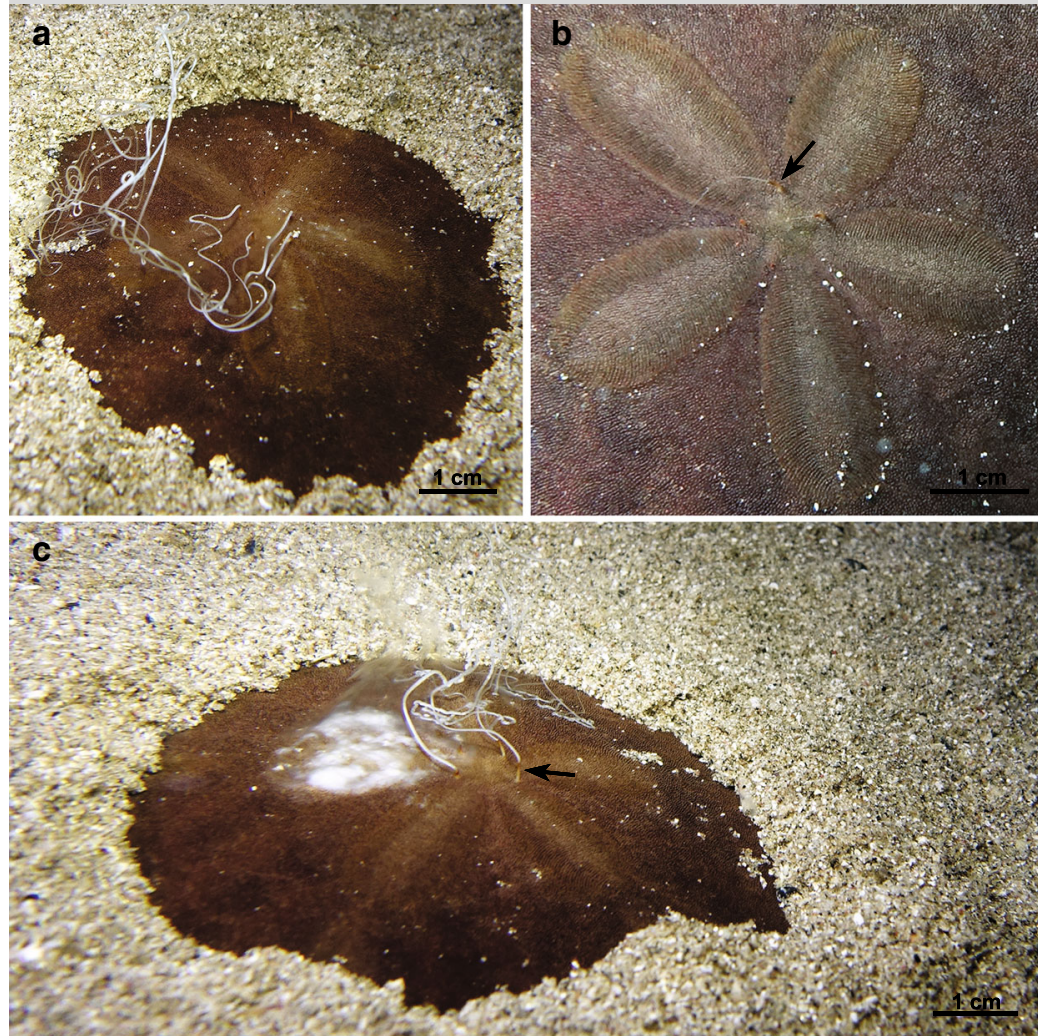

Fig. 1 Sculpsitechinus auritus spawning in situ. a Spurts of sperm. b Close-up of the exposed aboral surface. $\mathbf{c}$ The apical system of $S$. auritus exposed during spawning and genital papillae elongated. Arrows indicate the genital papillae auritus precedes spawning and that gamete release through the genital papillae may aid in propelling the gametes away from the animal's body into the
surrounding currents, hence sustaining their dispersal. References

Chia FS (1977) Structure and function of the genital papillae in a tropical sand dollar, Arachnoides placenta (L.) with a discussion on the adaptive significance of genital papillae in echinoids. J Exp Mar Bio Ecol 27:187-194

Mercier A, Hamel JF (2009) Endogenous and exogenous control of gametogenesis and spawning in echinoderms. Adv Mar Biol 55:1-302

Vellutini BC, Migotto AE (2010) Embryonic, larval, and juvenile development of the sea-biscuit Clypeaster subdepressus (Echinodermata:Clypeasteroida). PLoS One 5:e9654

T. Shlesinger $(\bowtie)$. Y. Loya

Department of Zoology, Tel-Aviv University, Tel-Aviv, Israel

e-mail: tomshlez@gmail.com

O. Bronstein

The Steinhardt Museum of Natural History, Tel-Aviv University, Tel-Aviv,

Israel

O. Bronstein

Natural History Museum Vienna, Burgring 7, 1010 Vienna, Austria

Received: 24 November 2015 / Accepted: 9 January 2016/Published online: 20 January 2016

(C) Springer-Verlag Berlin Heidelberg 2016

Coral Reefs (2016) 35:327 DOI 10.1007/s00338-016-1399-y (Mercier and Hamel 2009). Although most species shed their gametes directly through gonopores, some bear enital papillae, elongated protuberances extending from charge of gametes away from the spawning animal and to promote the dispersal of gametes through a thin layer of sand, enabling burrowing species to remain unexposed (Chia 1977). In contrast to early assumptions, recent reports of the reproductive behavior of Clypeaster subdepressus showed that despite having genital papillae, spawning was initiated only after the apex system was cleared from sand (Vellutini and Migotto 2010). These reports highlight the need for direct field observations of spontaneous spawning to better understand the external fertilization dynamics of clypeasteroids.

Here, we present the first field observations of a clypeasteroid spawning in its natural environment, and report the presence of genital papillae in Sculpsitechinus auritus (Leske, 1778) (formerly Echinodiscus auritus). During extensive surveys of reproduction of coral and other invertebrates at the Coral Beach Nature Reserve at Eilat, Red Sea $\left(29^{\circ} 30^{\prime} 12.0^{\prime \prime} \mathrm{N}, 34^{\circ} 55^{\prime} 07.5^{\prime \prime} \mathrm{E}\right)$, three male $S$. auritus were observed spawning on sand patches adjacent to corals. Spawning occurred during high tide, at depths of 1-3 m, between 2120 and $2135 \mathrm{hrs}$ on August 4, 2015, four nights after the full moon. Prior to spawning, $S$. auritus emerged from the sediment, completely exposing its aboral surface. Shortly after, spurts of sperm (Fig. 1a) were observed ejecting through the four genital papillae (Fig. 1b, c). Our observations suggest that complete exposure of the apical region in $S$.

The majority of echinoids are gonochoristic spawners 